\title{
Otimização do fluxo de materiais através da manufatura celular
}

\author{
Samuel Vieira Conceição \\ Departamento de Engenharia de Produção - UFMG
}

\begin{abstract}
Resumo
Nas indústrias cujo sistema de produção é caracterizado pelo sistema job shop, os fluxos de fabricação são complexos e as máquinas são agrupadas por processo, oferecendo um alto grau de flexibilidade em termos de variedade de produtos. Entretanto, essa flexibilidade é acompanhada de elevados tempos de setup, alto volume de estoque de produtos em processo e baixo volume de produção. Este artigo evidencia como a manufatura celular, particularmente a Análise do Fluxo de Fabricação (AFF), pode ser utilizada para otimizar o fluxo de materiais. A aplicação da metodologia AFF em uma pequena empresa do setor moveleiro possibilitou a formação de grupo de máquinas em células, com a obtenção de um novo fluxo de materiais, mais simplificado, com um layout melhor, um melhor reordenamento das operações-chave de produção e ganhos de produtividade.
\end{abstract}

\section{Palavras-chave}

Células de manufatura, análise do fluxo de fabricação, planejamento da produção, job shop.

\section{Flows materials optimization through cellular manufacturing}

\begin{abstract}
Machine layout in a job shop production system is basically a process where machines performing similar processes are grouped together. By physically grouping identical machines together, this production systems offers a high degree of flexibility. However, this flexibility entails many problems, such as high setup costs, inefficient material flow, high inventory cost and low productivity.

To circumvent the above mentioned problems, this paper presents a methodology based on production flow analysis. The experimental study took place in a corporation of the furniture industry. The results on cellular manufacturing and production flow analysis show that this methodology was able to reduce material handling time, setup time and throughput time. In addition, a new cellular layout was achieved.
\end{abstract}

\section{Key words}

Cellular layout, production flow analysis, production planning, job shop. 


\section{INTRODUC̣̃̃O}

A formação de células é uma das principais etapas no projeto de um sistema de manufatura celular. Envolve o agrupamento de peças em famílias de peças e o agrupamento de máquinas em células de manufatura, sendo esse sistema também conhecido como Tecnologia de Grupo. Teoricamente, a solução ótima para o problema de formação de células é a obtenção de células de manufatura completamente independentes. Isso significa que nenhuma peça deve ser processada em mais de uma célula de manufatura. Nos problemas encontrados nas empresas, as células de manufatura independentes são difíceis de se obter, pois geralmente ocorre que uma ou mais peças necessitam ser processadas em mais de uma célula, caracterizando a ocorrência de fluxo intercelular. Nesse caso específico, o principal objetivo na solução de um problema de formação de células é a determinação do grupamento de máquinas em células que minimiza o fluxo intercelular.

O problema da formação de células tem sido objeto de inúmeras pesquisas, devido a sua elevada importância nos projetos de arquitetura dos sistemas de produção organizados em células de manufatura. Uma das principais metodologias utilizadas para resolver esse problema é a análise do fluxo de fabricação - AFF (BURBIDGE 1963, 1992).

A AFF utiliza uma matriz de incidência de peças, isto é, uma matriz binária a qual indica se uma determinada máquina é utilizada ou não no processamento de uma peça. A matriz é rearranjada no formato de bloco diagonal, no qual as combinações máquina-peça são agrupadas em células ao longo da diagonal da matriz. Os elementos que estão fora do bloco diagonal denotam a existência de peças que necessitam ser processadas em mais de uma célula, o que caracteriza a existência de fluxo intercelular. Essa metodologia é utilizada no presente artigo para resolver o problema de formação de células em uma pequena empresa do setor moveleiro.

\section{REVISÃO DE LITERATURA}

\section{Manufatura celular}

O problema de formação de células tem sido objeto de inúmeras pesquisas devido a sua relevância no desenho dos sistemas de manufatura capazes de conferir maior flexibilidade de resposta às exigências dos clientes. A formação de células é uma das principais etapas no desenho e implementação de um sistema de manufatura celular, no qual a arquitetura dos sistemas de produção direciona os indicadores de desempenho dos sistemas produtivos, em termos de qualidade, flexibilidade, volume, custos de produção, confiabilidade e velocidade de entrega. O problema de formação de células envolve o agrupamento de peças em famílias de peças e o agrupamento de máquinas em células de manufatura, de modo que as peças com necessidades de processamento similares possam ser completamente manufaturadas na mesma célula.

Dois sistemas básicos podem ser utilizados para organizar a produção: o sistema de produção por produto e o sistema de produção por processo. Nos sistemas de produção cuja arquitetura privilegia a organização por produto, as máquinas são dispostas em linhas de produção dedicadas à fabricação de produtos específicos. Essa forma de organizar a produção apresenta certas vantagens, como o baixo custo de movimentação de materiais, pequenos níveis de estoque de produtos em processo e elevado grau de controle das atividades de produção. Embora apresente elevadas taxas de produção, esse sistema é pouco flexível, não permitindo a obtenção de vantagens referentes à economia de variedade (XAMBRE \& VILARINHO, 2003).

Nos sistemas de produção organizados por processo, as máquinas com a mesma funcionalidade são agrupadas em departamentos, de modo a facilitar o deslocamento das peças que necessitam de processamento em mais de um tipo de máquina. Esse modo de organizar a produção é relativamente flexível, além de favorecer uma alta taxa de utilização dos recursos. A organização por processo induz o sistema de produção a ter elevados níveis de estoque de produtos em processo, elevados níveis de movimentação de materiais, além de dificultar as tarefas de controle da produção (op. cit.).

Os sistemas produtivos nos quais a arquitetura é organizada através de células de manufatura são atualmente uma das principais estratégias de produção utilizadas pelas organizações, conseguindo somar as vantagens dos sistemas de produção orientados por produto e por processo. A manufatura celular quebra o paradigma de que não é possível obter simultaneamente vantagens de economia de variedade e médias taxas de produção.

A manufatura celular (MC) é caracterizada pelo grupamento de uma ou mais máquinas ligadas pela movimentação conjunta de materiais, sob o controle de uma célula centralizadora, com o objetivo de atender as necessidades de fabricação de uma família de peças (BURBIDGE 1989, GRZNAR, 1997). As peças são agrupadas em famílias dependendo de certas características, como similaridade da geometria das mesmas ou dos processos de fabricação (WEMMERLOV e JOHNSON, 1997; OLORUNNIWO \& GODWIN, 2002). Essa definição de manufatura celular enfatiza sobretudo o sentido de configuração conceitual de hardware, além do objetivo geral de um sistema de manufatura celular automatizado (CHEN et al., 2001). Essa definição coloca ainda uma ênfase muito acentuada na questão do problema de como 
fazer o agrupamento de máquinas e na formação de células, tratando de maneira muito simplificada o problema da integração entre tempo, espaço e informação na definição do sistema de manufatura celular (YAUCH \& STEUDEL, 2002). Uma definição mais abrangente para células de manufatura envolvendo a conexão entre tempo, espaço e informação é proposta por Hyer e Brown (1999). Esses autores definem células de manufatura como um problema de agrupar máquinas e peças de uma família de produtos com processos similares através da criação de um fluxo de trabalho no qual as tarefas e os operários que as executam estão perfeitamente conectados através dos elementos de ligação tempo, espaço e informação. Essa definição permite explicitar mais enfaticamente a ligação entre pessoas, tarefas, fluxo de informação e fluxo de materiais com a célula de manufatura. Assim, a introdução do elemento de ligação "tempo" na definição acima tem o papel de minimizar a transferência e os tempos de espera entre tarefas seqüencialmente dependentes. O elemento de ligação "espaço" permite que todas as tarefas sejam executadas levando-se em consideração a proximidade entre as células, com o objetivo de minimizar os tempos de deslocamento, que não agregam valor ao produto. Finalmente, o elemento de ligação "informação" permite que as pessoas e as máquinas responsáveis pela execução das atividades nas células tenham acesso completo à informação sobre a disposição das tarefas (jobs) nas células. A definição proposta por Hyer e Brown (op. cit.) permite que o processo de conversão de um dado sistema de produção para o sistema de manufatura celular seja dividido nas seguintes etapas (YAUCH et al. Op. cit.):

i) Formação: refere-se à criação conceitual das células, a qual é feita através da análise da matriz máquina-peça, e a subseqüente divisão em famílias de peças, cuja similaridade permite a produção das mesmas em grupo de máquinas;

ii) Desenho da célula: refere-se à determinação dos parâmetros operacionais da célula, incluindo, entre outros, tamanho do lote, número de operadores e layout da célula;

iii) Implementação: refere-se ao processo de colocar em operação as modificações sugeridas durante o processo de formação de células;

iv) Operação: refere-se ao funcionamento diário das células.

Qualquer que seja o conceito adotado, a avaliação da performance do sistema de manufatura celular necessita ser avaliada a fim de permitir a mensuração dos ganhos tangíveis e intangíveis obtidos com esse sistema. A avaliação consiste em analisar periodicamente o desempenho do sistema de células através de indicadores e metas previamente estabelecidos.

Os dois principais indicadores utilizados para avaliar a performance do sistema de MC são baseados em indicadores físicos e sociais. Os indicadores físicos procuram mensurar a performance do sistema de MC através da eficiência no desenho do layout, isto é, da similaridade entre peças e processos de manufatura obtidos através do reordenamento das operações e agrupamento de peças em famílias (HASSAN, 1995; CHING et al., 1999); da redução no tempo de setup, da redução do estoque de produtos em processo, da redução na taxa de retrabalho, através do aumento na taxa de ocupação das máquinas, alem dos potenciais ganhos na velocidade de produção e confiabilidade na entrega dos produtos (SELIM et al., 1998; KANNAN \& PALOCSAY, 1999).

A performance obtida na implementação de um sistema de manufatura celular também tem sido analisada do ponto de vista social, isto é, do processo de aprendizagem, fatores culturais e das mudanças sociais que ocorrem na empresa. Yauch e Steudel (2002), através de dois estudos de caso exploratórios, mostram como a cultura organizacional impacta o processo de implementação de um sistema de manufatura celular. Eles identificaram os seguintes fatores culturais que impactam o processo de conversão para manufatura celular em pequenas empresas: sistema organizacional fraco, transferência de responsabilidade, falta de respeito mútuo e confiança, complacência, fronteiras rígidas entre os grupos, foco no cliente externo, excesso de ênfase em atividades rotineiras e crise de mobilidade.

\section{Técnicas de formação de células}

Várias metodologias podem ser utilizadas para agrupar peças e máquinas em famílias:(i) classificação e codificação, (ii) análise dos fluxos de fabricação (AFF), (iii) programação matemática, (iv) simulação, (v) algoritmos genéticos e (vi) metodologias baseadas em inteligência artificial (MELLER \& GAU,1996; LIANG \& ZOLFAGHARI,1998; PROUDLOVE et al., 1998; VENUGOPAL, 1999).

Uma análise estatística detalhada da aplicação dos diversos métodos encontrados na literatura é apresentada por REISMAN et al. (1997). A análise conduzida pelos autores evidencia que algumas dessas metodologias apenas conseguem determinar a melhor configuração de famílias de peças, enquanto outras além de identificarem a melhor configuração da família de peças a ser formada, também identificam o grupo de máquinas que formarão as células. Os métodos que apenas determinam a melhor configuração da família de peças fornecem apenas uma solução parcial para o problema de formação de células, visto que uma vez solucionado o problema do agrupamento de peças em famílias, faltaria ainda determinar as máquinas necessárias para processar as peças em deter- 
minada célula. Esses métodos são baseados em sistemas de classificação e codificação, nos quais o agrupamento de peças é feito baseado no conceito de similaridade de processo, isto é, o agrupamento de peças é realizado de acordo com o coeficiente de similaridade, sendo o método da p-mediana um dos mais citados na literatura (KUSIAK, 1985; XAMBRE \& VILARINHO, 2003). Quanto maior o valor do coeficiente, maior o grau de similaridade entre as peças. O coeficiente de similaridade representa o grau de atividades similares ou comuns entre duas peças ou duas máquinas, isto é, o coeficiente de similaridade mensura o grau de grau de atividades similares ou comuns entre duas peças em termos do número de máquinas no qual essas peças são processadas. Analogamente, o coeficiente de similaridade entre duas máquinas mensura o grau de grau de atividades similares ou comuns entre as duas máquinas em termos do número de peças processadas. Assim, o coeficiente de similaridade entre todas as peças ou máquinas é representado em termos de uma matriz de coeficiente de similaridade (KUSIAK, 1987; KUSIAK \& CHOW, 1987; WEI e KERN, 1989; TAM, 1990).

Os métodos que além de determinar a família de peças também determinam a família de máquinas são geralmente baseados na matriz de incidência peça-máquina. Esses métodos podem ser divididos em: (i) grupamentos hierárquicos e não-hierárquicos, (ii) métodos baseados em programação matemática, (iii) em teoria dos grafos, (iv) redes neurais e (v) métodos heurísticos e metaheurísticos (VENUGOPAL \& NARENDRAM, 1994; SINGH, 1993; SELIM et al., 1998).

No caso da presente pesquisa, a ênfase é dada na utilização da metodologia de Análise do Fluxo de Fabricação, uma metodologia que identifica as famílias de peças e os grupos de máquinas.

A AFF utiliza uma matriz binária de incidência de peças, a matriz peça-máquina, para indicar se uma máquina é ou não utilizada para processar uma peça. A matriz é rearranjada na forma de blocos diagonais, conhecida como matriz BDF (block diagonal form), na qual os blocos de peça-máquina são agrupados em células ao longo da diagonal da matriz. Os elementos da matriz BDF não pertencentes à diagonal da matriz configuram a existência de fluxo intercelular. Nesse caso, o AFF propõe que esses fluxos intercelulares sejam solucionados através da duplicação de máquinas, da subcontratação de serviços ou através de mudanças nos roteiros de produção.

A Análise por Grupo (AG) é uma das etapas mais importantes da metodologia AFF. Nessa fase, deve-se proceder à análise das máquinas de cada estágio do sistema de produção, dividindo-as em grupos e quantificando o fluxo de operações entre elas. Essa etapa tem como obje- tivo principal a formação de grupos de máquinas que produzam todas as peças neles envolvidas e que apresentem as condições necessárias para a execução das tarefas (jobs) nas instalações físicas existentes na fábrica. A AG é baseada na formação de pequenos módulos, agrupados em uma série de máquinas-chave. Por definição, máquinachave é a máquina mais importante de cada módulo, sendo possível que um módulo tenha mais de uma máquinachave. Cada módulo consiste em um conjunto de peças e máquinas envolvidas entre si. Isso implica que existe uma grande probabilidade de que peças contidas em cada módulo se ajustem em um grupo comum, de modo que os módulos serão combinados para a formação dos grupos.

Vários fatores influenciam a formação de grupos de peças, como compatibilidade de processos, similaridade entre peças e/ou máquinas, utilização de máquinas especiais, utilização do mesmo tipo e/ou forma do material (aço, alumínio, barra, tubo ou chapa) ou ainda se as peças contidas nesses módulos têm as mesmas formas básicas e/ ou funções.

Portanto, a Análise do Fluxo de Fabricação (AFF) é uma técnica de melhoria do layout da fábrica, permitindo que a empresa obtenha ganhos tangíveis e intangíveis. Essa forma de organizar a produção traz, segundo BURBIDGE (1989), as seguintes vantagens: menor tempo de fabricação devido à menor distância percorrida, menor quantidade de produtos em processo, devido a uma redução no tempo de fabricação, baixo custo de implementação, menor número de ordens de fabricação, maior qualidade do produto e maior satisfação no trabalho.

\section{METODOLOGIA}

O estudo de caso foi utilizado como metodologia tanto pelas oportunidades geradas de investigação de questões "como "e "por quê", quanto pela oportunidade de desenvolvimento de novas teorias e idéias que podem colaborar no refinamento da teoria existente (YIN, 1994). A aplicação da AFF foi conduzida conforme as seguintes etapas:

Etapa 1: Utilizou-se o princípio de Pareto (curva $\mathrm{ABC}$ ) para selecionar os principais produtos da empresa em termos da margem de contribuição. Esses produtos foram objeto do estudo de melhoria de fluxo e layout. Por definição, a margem de contribuição é a diferença entre o preço de venda e os custos variáveis de produção.

Etapa 2: Desdobramento da AFF. A AFF foi dividida nas seguintes etapas: análise de fluxo entre departamentos (seções produtivas), análise por grupos e linha.

Etapa 3: A partir da aplicação da metodologia AFF, propõe-se a formação de grupos de máquinas em células, com o objetivo de obter um novo fluxo, mais simplificado, com um melhor layout e ganhos de produtividade. 


\section{ESTUDO DE CASO}

\section{0 cenário competitivo}

A pesquisa sobre a implementação do sistema de manufatura celular foi feita em uma média empresa do setor moveleiro. No início dos anos 90, a empresa experimentou um grande crescimento nas vendas e implantou filiais em vários Estados das regiões Sul e Sudeste do Brasil. O surgimento de novos atores no mercado mudou o cenário e acirrou a competição com grande reflexo na redução no preço dos produtos e aumento no nível de serviço oferecido ao cliente. Esse último, traduzido em termos de prazo de entrega, confiabilidade de entrega, flexibilidade e qualidade dos produtos.

O novo cenário acarretou a perda de partes significativas do mercado, com fechamento das filiais em vários Estados. A empresa oferecia um vasto porta-fólio de produtos, que incluía desde produtos padronizados a uma extensa gama de produtos feitos sob encomenda, com grandes diferenças nas especificações técnicas dos mesmos. $\mathrm{O}$ atendimento à customização de produtos conferia flexibilidade à empresa, mas trazia reflexos negativos em termos de elevados custos de produção e prazos de entrega maiores que os praticados pela concorrência.

Diante desse cenário, a melhoria no processo produtivo necessitava de uma investigação científica que apontasse soluções que redirecionassem a posição competitiva da empresa.

Portanto, a utilização de técnicas de manufatura celular, como a análise do fluxo de fabricação, poderia contribuir para minimizar o processo de perda de competitividade da empresa. A escolha da técnica AFF deu-se em função da sua fácil aplicação, da facilidade de obtenção de resultados rápidos e da facilidade de se fazer análises comparativas com a situação originalmente encontrada.

\section{Aplicação da técnica AFF}

Através de uma análise conduzida na empresa, de acordo com as etapas descritas na metodologia acima, foi possível segmentar o processo produtivo em departamentos, processos e máquinas, conforme mostrado na Tabela 1.

Da mesma forma, foi necessário listar todas as máquinas utilizadas no processo produtivo e assim estabelecer um código, conforme mostrado na Tabela 2.

Tabela 1: Códigos dos departamentos.

\begin{tabular}{|l|c|}
\hline \multicolumn{1}{|c|}{ DEPARTAMENTO } & CóDIGO \\
\hline Corte & 1 \\
\hline Prensa & 2 \\
\hline Viradeira Elétrica / Viradeira Manual & 3 \\
\hline Ponteadeira-Solda Elétrica & 4 \\
\hline Solda Mig / Maçarico-Solda arco elétrico & 5 \\
\hline Lixadeira & 6 \\
\hline Limpeza & 7 \\
\hline Pintura & 8 \\
\hline Montagem final & 9 \\
\hline
\end{tabular}

Tabela 2: Códigos das máquinas.

\begin{tabular}{|c|c|}
\hline MÁQUINAS & CÓDIG0S \\
\hline Tesouras & T2,T3,T4 \\
\hline Prensas & S1,S2,S3,S4,S5,S6,S7,S9,S10 \\
\hline Viradeiras & V1,V2,V3,V4,V5 \\
\hline Viradeiras manuais & P1,P2,P4,P5,P6,P7,P8 \\
\hline Soldas elétricas & M1 \\
\hline Solda mig & MA \\
\hline Solda maçarico & LM \\
\hline Lixadeira & PI,PJ \\
\hline Limpeza & MF \\
\hline Pintura & \\
\hline Montagem &
\end{tabular}


A obtenção das Tabelas 1 e 2, demandou um esforço adicional na obtenção dos dados, visto que, do ponto de vista de organização da produção, a empresa apresentava um grave quadro, sem nenhuma formalização do fluxo de informações e de materiais. Como relatado em Yauch e Steudel (2002), a falta de organização, isto é, a falta de um sistema estruturado de políticas e procedimentos formais, dificulta a implementação da Manufatura Celular (MC) nas organizações. Da mesma forma, pesquisas conduzidas por Brown (1980) no processo de implementação de manufatura celular apontam que a falta de organização leva a uma dissipação de energia e perda de competitividade devido à falta de uma estratégia e de procedimentos formais. Embora a investigação sobre a existência de um sistema organizacional não fosse o objeto da pesquisa, nota-se que, assim como relatado na literatura, a empresa em questão não dispunha de procedimentos formais sobre o fluxo de informação e de materiais que possibilitassem estabelecer uma análise refinada entre departamentos produtivos, códigos das máquinas e outras informações relevantes ao processo de aplicação da metodologia AFF e implementação da MC. Após o levantamento preliminar de informações, o próximo passo da pesquisa foi a aplicação da AFF.

\section{Aplicação da Análise do Fluxo de Fabricação}

A AFF é uma técnica capaz de agrupar produtos e/ou componentes a fim de simplificar o fluxo da produção da fábrica e eliminar aqueles que não agreguem valor ao produto. A aplicação da AFF foi dividida em duas etapas principais: análise de fluxo entre departamentos e análise por grupos e linha.

\section{Análise de Fluxo entre Departamentos (AFD)}

Essa etapa foi conduzida segmentado-se o fluxo em dois módulos: i) levantamento atual do fluxo de produção e ii) simplificação do fluxo obtido no módulo "i".

Nessa etapa, os fluxos semelhantes são agrupados de maneira a simplificar o fluxo de produção, selecionandose as peças com maior volume de produção, agrupando-as em estágios de fabricação, obtendo-se como resultado um fluxograma chamado de "predominante simplificado".

O objetivo de se levantar o fluxo atual de produção foi encontrar um fluxo de materiais entre os departamentos ou seções produtivas que fosse simples e eficiente. Esse fluxo foi obtido através dos seguintes passos: i) determinação do número de fluxo de processo (NFP) e ii) desenho e simplificação do fluxograma básico.

O primeiro passo consistiu em determinar os números de fluxos de processo (NFP) para posteriormente sumarizar os resultados numa tabela de freqüência de NFP. O número de fluxo de processo (NFP) é um código numérico que faz a listagem dos códigos de todas as unidades de processamento (departamentos) na mesma seqüência em que são utilizadas na fabricação da peça. Por exemplo: departamento de corte (1), prensa (2), viradeira (3), solda (4). O código 1234 significa um NFP para uma peça que começa no departamento 1 (corte), visita os departamentos 2 (prensa) e 3 (viradeira) e finalmente visita o departamento 4 (solda).

Os NFP de todas as operações obtidas na empresa são mostrados na Tabela 3, com um total de 52 NFPs.

A obtenção de dados técnicos referentes às máquinas, processos de fabricação, produtos e peças, assim como informações referentes ao sistema de planejamento e controle da produção também foi uma tarefa árdua, devido à falta de informação na empresa. Nessa etapa foi necessário contatar diretamente o fabricante de algumas máquinas, fazer todos os roteiros de produção, codificar

Tabela 3: Freqüência dos Números de Fluxos de Processo (NFP).

\begin{tabular}{|c|c|c|c|}
\hline $\begin{array}{c}\text { NÚMERO DE FLUXO DE } \\
\text { PROGESSO (NFP) }\end{array}$ & QUANTIDADE & $\begin{array}{c}\text { NÚMERO DE FLUXO DE } \\
\text { PROCESSO (NFP) }\end{array}$ & QUANTIDADE \\
\hline 123234 & 1 & 12389 & 2 \\
\hline 12324 & 1 & 124 & 2 \\
\hline 123246789 & 3 & 1249 & 2 \\
\hline 1234 & 15 & 12789 & 2 \\
\hline 12343 & 2 & 1324 & 1 \\
\hline 123456 & 1 & 132789 & 4 \\
\hline 12348 & 1 & 134 & 2 \\
\hline 12354 & 6 & 134678 & 1 \\
\hline 123546 & 4 & 135 & \\
\hline 123789 & 1 & & $\mathbf{5 2}$ \\
\hline TOTAL & \multicolumn{3}{|l}{} \\
\hline
\end{tabular}


peças e produtos para facilitar o manuseio e tratamento dos dados.

A inexistência de procedimentos formais de planejamento e controle da produção em pequenas e médias empresas (PME) é discutida por Slopm e Zijm (1993), os quais apontam várias vantagens que a implementação da $\mathrm{MC}$ oferece às PME. Esses autores argumentam que para que a empresa obtenha tais vantagens é necessário que ela tenha um sistema de planejamento e controle da produção (PCP) bem desenhado, beneficiando-se assim das vantagens de eficiência, flexibilidade e multifuncionalidade que a MC propicia. No caso em estudo, a empresa não possuía um sistema de PCP, o que de certa forma dificultou a tarefa de obtenção dos NFP e do desenho do fluxograma produtivo da empresa, sendo necessário um consumo adicional de tempo para levantar, validar e analisar as informações. Ficam assim evidenciados vários obstáculos na implementação da MC decorrentes da inexistência de sistemas formais de planejamento e controle, principalmente nas PME.

Passo 2: Desenho do fluxograma básico: a tabela de freqüência de NFP fornece os dados necessários para desenhar o fluxograma básico. Este fluxograma foi construído desenhando-se as operações e ligando-as através de setas, de acordo com as seqüências dos NFPs, para um total de nove departamentos, conforme Figura 1.

Nesse segundo módulo, simplifica-se o fluxograma básico (utilizando-se os dados da Tabela 3), considerando-se possíveis restrições, ou seja, especificam-se quais unidades de processamento não devem ser unidas devido à existência de restrições, como por exemplo a incompatibilidade de processos produtivos.

O processo de simplificação do fluxograma básico foi conduzido através dos seguintes passos: i) desenho do fluxograma predominante e ii) simplificação por combi- nação. No desenho do fluxograma predominante determinaram-se os NFPs pelos quais passa o maior número de peças, e então foi construída uma tabela de freqüência de NFP em ordem decrescente do número de peças, conforme mostrado na Tabela 4.

Figura 1: Fluxograma básico original da fábrica.

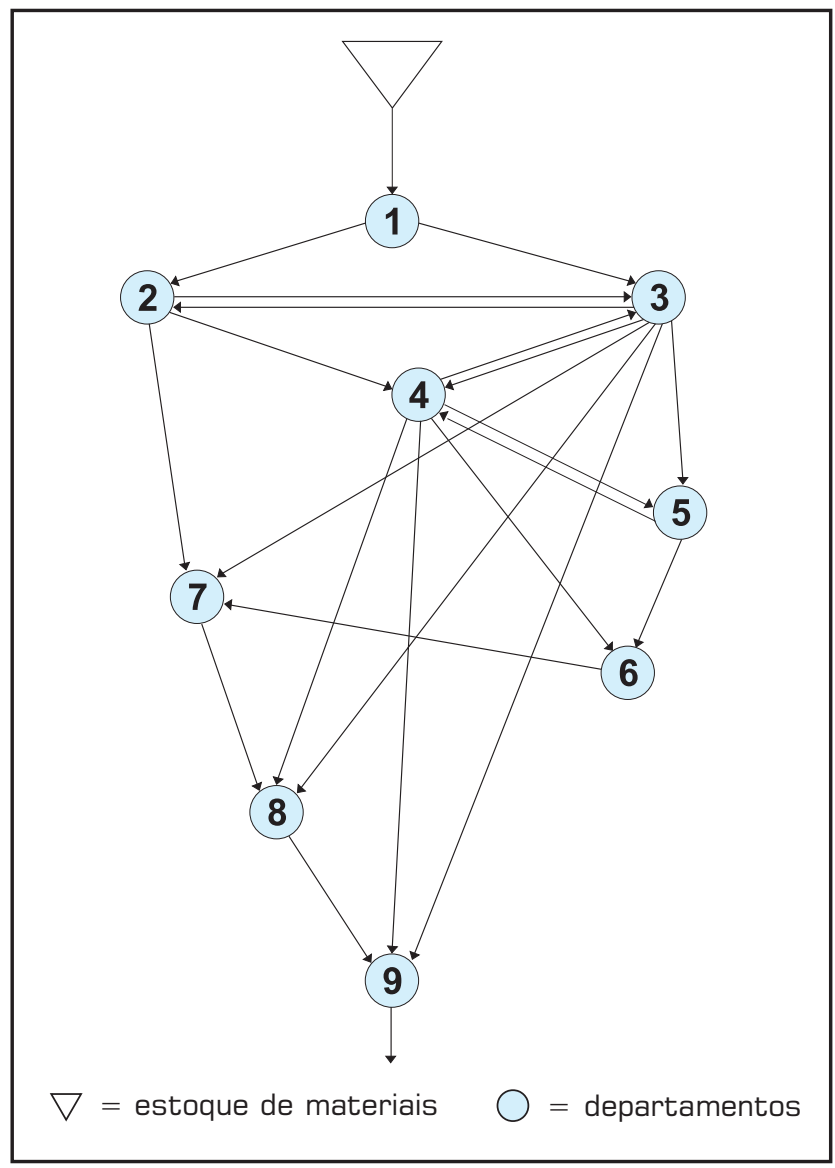

Tabela 4: Freqüência dos Números de Fluxos de Processo (NFP).

\begin{tabular}{|c|c|c|c|}
\hline NFP & QUANTIDADE & NFP & QUANTIDADE \\
\hline 1234 & $15^{*}$ & 134678 & 2 \\
\hline 12354 & $6^{*}$ & 123234 & 1 \\
\hline 123546 & $4^{*}$ & 12324 & 1 \\
\hline 134 & $4^{*}$ & 123456 & 1 \\
\hline 123246789 & $3^{*}$ & 12348 & 1 \\
\hline 12343 & 2 & 123789 & 1 \\
\hline 12389 & 2 & 1324 & 1 \\
\hline 124 & 2 & 132789 & \\
\hline 1249 & 2 & 135 & $\mathbf{5 2}$ \\
\hline 12789 & 2 & & \\
\hline TOTAL & \multicolumn{3}{|l}{}
\end{tabular}


$\mathrm{Na}$ Tabela 4, pode-se observar que 32 peças das 52 produzidas (indicadas com asterisco) correspondem a $62 \%$ do total e são cobertas por $25 \%$ dos NFPs. Os NFP marcados com asteriscos não necessariamente representam os NFPs mais freqüentes. Entretanto, é importante uma análise desses NFPs em conjunto com os dados da curva $\mathrm{ABC}$, pois existe a possibilidade de um NFP ter frequiência alta, porém pertencer a produtos pouco fabricados. De modo análogo, pode existir um NFP pouco freqüente, mas que é parte de um dos produtos com maior frequiência. Essa é uma forma de garantir que os NFPs mais freqüentes correspondem aos produtos com maior volume de venda. Do ponto de vista metodológico, há ainda a possibilidade de verificar a relação entre os produtos com maior volume de venda e a margem de contribuição. Na empresa em questão, o cálculo da margem de contribuição dos produtos evidenciou que vários produtos tinham um lucro elevado, entretanto eles não tinham boa margem de contribuição, demonstrando assim a pertinência de estabelecer uma análise crítica entre os produtos fabricados, o número de fluxo de processos, a curva $\mathrm{ABC}$ e a margem de contribuição. Após essa

Figura 2: Fluxograma predominantemente simplificado.

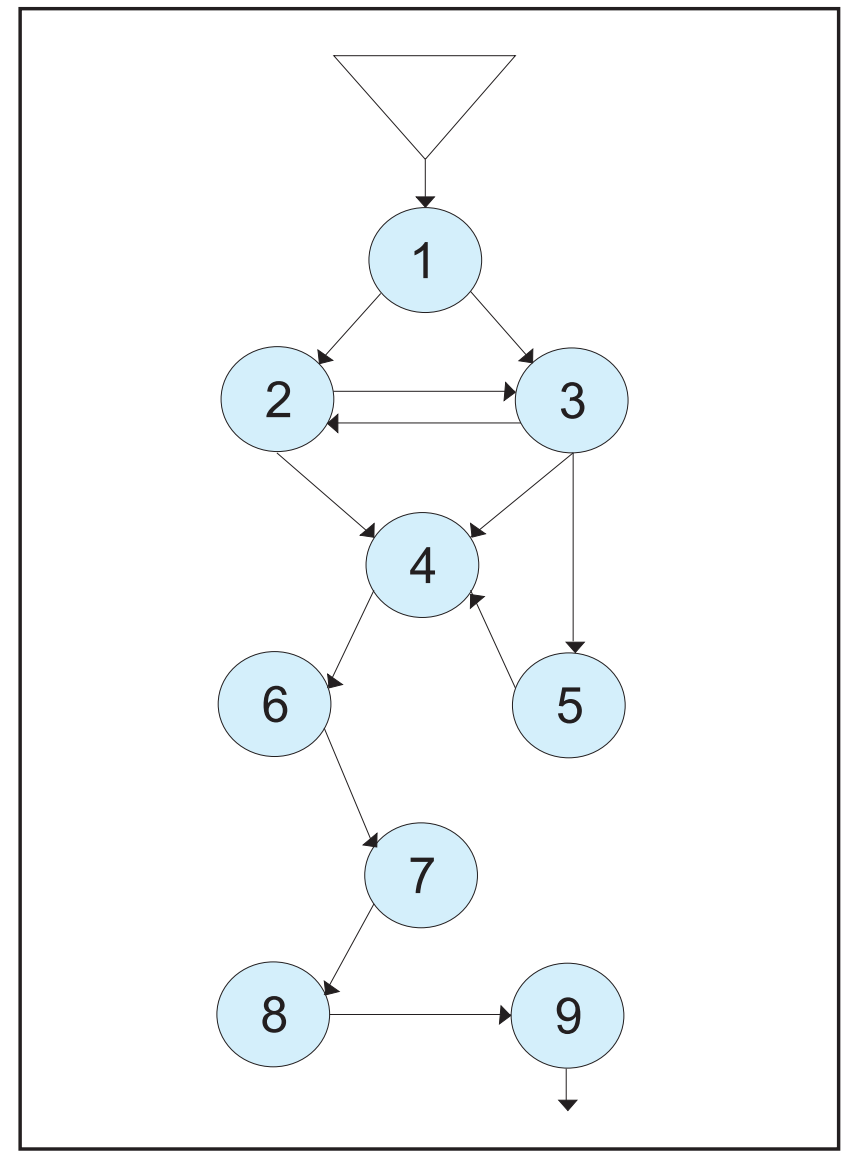

análise torna-se possível desenhar o fluxo predominante de maneira que ele realmente corresponda aos produtos com maior potencial de agregar valor para a empresa e seus clientes.

Assim, utilizando-se 32 das 52 peças ou aproximadamente $62 \%$ de NFPs, desenhou-se o fluxograma predominante, como mostrado na Figura 2.

Comparando-se a Figuras 1 com o fluxograma acima (Figura 2), observa-se que o fluxograma predominante oferece uma melhor visibilidade das diversas etapas do processo produtivo.

Outro fator importante, após a construção do fluxograma predominantemente simplificado, é verificar a existência de alguns NFPs que não se enquadram ou não contêm as principais peças fabricadas no fluxograma predominante. No presente estudo quantificaram-se 17 NFPs (Tabela 4) que não se enquadravam no fluxograma predominante.

Agrupando-se os 17 NFPs acima com a tabela de freqüência de NFP em ordem decrescente do número de peças (Tabela 4), obtém-se a Tabela 6 com os NFPs mais significativos. A elaboração dessa tabela tem o objetivo de subsidiar o processo de simplificação do fluxograma predominante.

Na Tabela 6, observa-se que 49 peças produzidas, as quais correspondem a $94 \%$ do total, são cobertas por $89 \%$ dos NFPs, o que caracteriza uma freqüência que consegue cobrir a quase totalidade dos produtos mais importantes fabricados pela empresa.

Para simplificar o fluxograma predominante foi necessário combinar, separar ou mover os departamentos, conforme a compatibilidade entre os processos de fabri-

Tabela 5: NFPs que não se enquadram no fluxograma predominante.

\begin{tabular}{|c|c|}
\hline NFP & QUANTIDADE \\
\hline 123234 & 1 \\
\hline 12324 & 1 \\
\hline 123456 & 1 \\
\hline 123789 & 1 \\
\hline 12389 & 2 \\
\hline 124 & 2 \\
\hline 1249 & 2 \\
\hline 12789 & 2 \\
\hline 1324 & 1 \\
\hline 132789 & 1 \\
\hline 134678 & 2 \\
\hline 135 & 1 \\
\hline TOTAL & $\mathbf{1 7}$ \\
\hline
\end{tabular}


cação. Por exemplo, com base nos dados da Tabela 6, as atividades realizadas no departamento 1 (corte) foram movidas para dentro do estoque por representarem a preparação e início do processo produtivo. Os departamentos 2 (prensa) e 3 (viradeira) foram unidos em função da compatibilidade dos processos. Entretanto, os departamentos 4 e 5 (soldas) e 6 (lixa) apresentavam uma restrição quanto à incompatibilidade de processos com os departamentos de limpeza, pintura e montagem final, porque nesses locais não pode haver materiais em suspensão, o que levaria ao retrabalho dos produtos.

Dessa forma, com esses $89 \%$ de NFPs, simplificou-se o fluxo em $94 \%$ das principais peças fabricadas. Do ponto de vista de implementação, o principal obstáculo acontece quando o fluxograma predominante e o correspondente layout apontam para a necessidade de realização de obras de engenharia civil, notadamente as que exigem investimentos em fundações. Outro aspecto relevante é que quanto maior a variedade de produtos fabricados com roteiros de produção completamente diferentes, menor será o grau de simplificação obtido. No presente estudo, optou-se por eliminar do porta-fólio de produtos da empresa uma série de produtos customizados cuja demanda era sazonal e incipiente em quantidade. Essa redução é uma decisão de difícil aceitação, principalmente quando a estrutura organizacional da empresa tem uma forte base familiar.

Tabela 6: Tabela de freqüência dos NFP mais comuns.

\begin{tabular}{|c|c|}
\hline NFP & QUANTIDADE \\
\hline 1234 & 15 \\
\hline 12354 & 6 \\
\hline 123546 & 4 \\
\hline 134 & 4 \\
\hline 123246789 & 3 \\
\hline 123234 & 1 \\
\hline 12324 & 1 \\
\hline 123456 & 1 \\
\hline 123789 & 2 \\
\hline 12389 & 2 \\
\hline 124 & 2 \\
\hline 1249 & 2 \\
\hline 12789 & 1 \\
\hline 1324 & 1 \\
\hline 132789 & 2 \\
\hline 134678 & 1 \\
\hline 135 & $\mathbf{4 9}$ \\
\hline TOTAL & \\
\hline
\end{tabular}

Para concluir esta etapa, simplificou-se o fluxograma predominante, agrupando-se processos semelhantes em um mesmo estágio, conforme mostrado na Figura 3.

Comparando-se as Figuras 1 (fluxograma básico original) e 3 (fluxograma simplificado), observa-se que os fluxos estão mais enxutos, apresentando visibilidade no processo produtivo, menores distâncias entre operações e conseqüentemente menor movimentação de materiais, com reflexos positivos na agregação de valor ao produto. Uma vez concluído o fluxograma predominante simplificado, pôde-se então realizar o próximo passo, a formação de grupos.

\section{Aplicação da Análise por Grupos (AG)}

Existem dois passos principais necessários para a aplicação da análise por grupo: a formação de módulos e a formação de grupos. Assim sendo, o primeiro passo nessa etapa foi utilizar a classificação SICGE (BURBIDGE, 1989). A classificação SICGE é uma forma de classificar as máquinas segundo as categorias especiais (S), intermediárias (I), comuns (C), gerais (G) e de equipamentos (E).

Após a determinação de quais máquinas pertencem às diferentes categorias da classificação SICGE, iniciou-se a formação de módulos. Para isso, foi necessário construir a tabela de máquinas, a matriz peça $\mathrm{x}$ máquina e a tabela de módulo resumido. Para a construção da tabela

Figura 3: Fluxograma predominante simplificado.

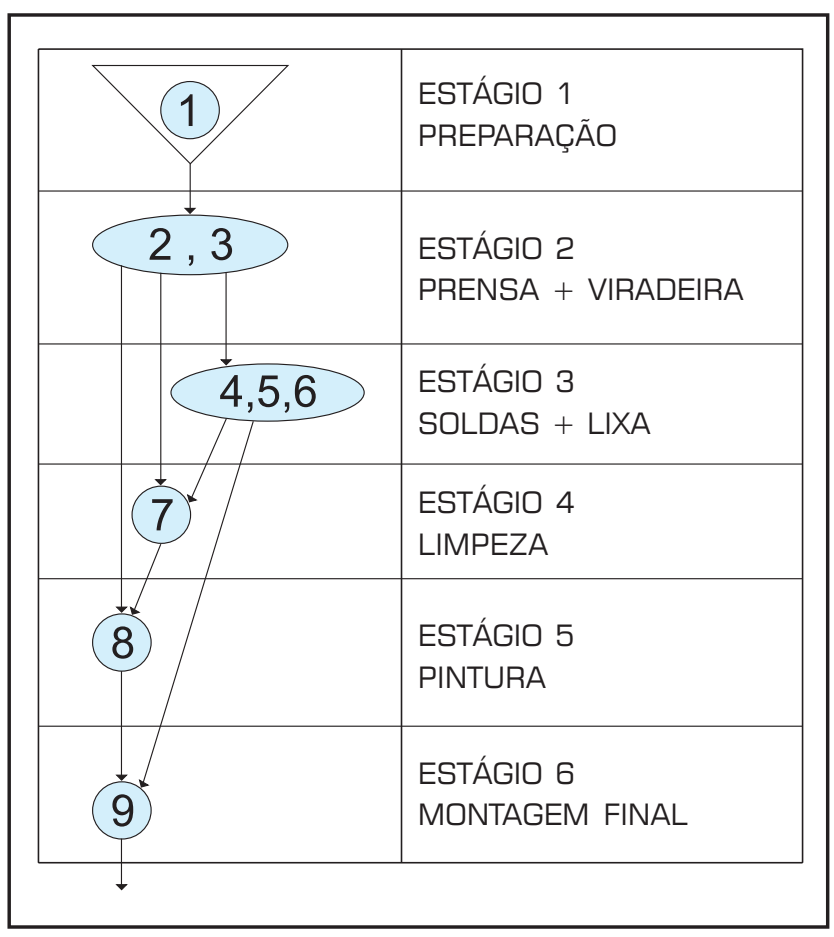


de máquinas, utilizou-se a classificação SICGE, conforme Tabela 7 .

Uma vez construída a tabela de máquinas, analisou-se quais máquinas eram iguais ou apresentavam similaridade (em tamanho, função e/ou capacidade) e quais executavam operações similares a outras máquinas e assinalou-se com um mesmo código as que eram similares. $\mathrm{Na}$ empresa em estudo, constatou-se que as máquinas $\mathrm{S} 1, \mathrm{~S} 2$ e $\mathrm{S} 3$ eram iguais e poderiam substituir todas as outras prensas (S5, S4, S6, S7, S9 e S10), devendo, portanto, ter o mesmo código (S1). Nesse caso, o objetivo é determinar um agrupamento de máquinas no

Tabela 7: Tabela de máquinas segundo a classificação SICGE.

\begin{tabular}{|c|c|c|c|}
\hline MÁQUINAS & CÓDIGO & SICGE & N \\
\hline Tesoura & $\mathrm{T} 4$ & S & 1 \\
\hline Tesoura & T2 & $G$ & 1 \\
\hline Tesoura & T3 & G & 1 \\
\hline Prensa & $\mathrm{s1} / \mathrm{s2} / \mathrm{s3}$ & $\mathrm{C}$ & 3 \\
\hline Prensa & S5 & C & 1 \\
\hline Prensa & S4 & C & 1 \\
\hline Prensa & S6 / S7 / S9 & $\mathrm{C}$ & 3 \\
\hline Prensa & $\mathrm{S10}$ & C & 1 \\
\hline Viradeira & V1 / V2 / V4 & 1 & 3 \\
\hline Viradeira & V3 / V5 & $\mathrm{C}$ & 2 \\
\hline Viradeira manual & VA / VB & $E$ & 2 \\
\hline Solda elétrica & $\begin{array}{c}\mathrm{P} 8 \\
\mathrm{P} 1 / \mathrm{P} 2 / \mathrm{P} 4 / \mathrm{P} 5 / \mathrm{P} 6 / \mathrm{P} 7\end{array}$ & $\begin{array}{l}\mathrm{S} \\
\mathrm{C}\end{array}$ & $\begin{array}{l}1 \\
6 \\
\end{array}$ \\
\hline Solda mig & M1 & $\mathrm{S}$ & 1 \\
\hline Solda maçarico & $\mathrm{Ma}$ & $\mathrm{S}$ & 1 \\
\hline Lixadeira manual & L1 & $\mathrm{S}$ & 1 \\
\hline
\end{tabular}

Tabela 8: Agrupamento resumido das máquinas segundo a classificação SICGE.

\begin{tabular}{|c|c|c|c|c|}
\hline MÓDULO & MÁQUINA & CÓDIGO & SICEE & $\mathbf{N}$ \\
\hline 1 & Tesoura & T4 & $\mathrm{S}$ & 1 \\
\hline 2 & Tesoura & $\mathrm{T} 2$ & $G$ & 1 \\
\hline 3 & Tesoura & T3 & G & 1 \\
\hline 4 & Prensa & S1 (S1-S2-S3) & C & 3 \\
\hline 5 & Prensa & S5 & C & 1 \\
\hline 6 & Prensa & S4 & C & 1 \\
\hline 7 & Prensa & S6 (S6-S7-S9) & C & 3 \\
\hline 8 & Prensa & 510 & C & 1 \\
\hline 9 & Viradeira & V1 (V1-V2-V4) & 1 & 3 \\
\hline 10 & Viradeira & V3 (V3-V5) & $\mathrm{C}$ & 2 \\
\hline 11 & Viradeira manual & VA (VA-VB) & $E$ & 2 \\
\hline 12 & Solda elétrica & P8 & $\mathrm{S}$ & 1 \\
\hline 13 & Solda elétrica & P1 (P1-P2-P4-P5-P6-P7) & C & 6 \\
\hline 14 & Solda mig & M1 & $\mathrm{S}$ & 1 \\
\hline 15 & Solda maçarico & $\mathrm{Ma}$ & $S$ & 1 \\
\hline 16 & Lixadeira manual & L1 & $\mathrm{S}$ & 1 \\
\hline
\end{tabular}


qual cada agrupamento é chamado de módulo. Então, cada módulo consiste em um conjunto de máquinas que contém o mesmo código. Assim, a máquina T4 é regis- trada como módulo 1; a máquina T2 como módulo 2; e a máquina $\mathrm{S} 1 \quad(\mathrm{~S} 1=\mathrm{S} 2=\mathrm{S} 3)$ como módulo 4 , e assim sucessivamente, conforme mostrado na Tabela 8.

Figura 4: Matriz peça(P) x máquina(M)

\begin{tabular}{|c|c|c|c|c|c|c|c|c|c|c|c|c|c|c|c|c|c|c|c|c|c|c|c|c|c|c|c|c|c|c|}
\hline $\mathbf{P}$ & 1 & 2 & 3 & 4 & 5 & 6 & 7 & 8 & 9 & 10 & 11 & 12 & 13 & 14 & 15 & 16 & 17 & 18 & 19 & 20 & 21 & 22 & 23 & 24 & 25 & 26 & 27 & 28 & 29 & 30 \\
\hline M & & & & & & & & & & & & & & & & & & & & & & & & & & & & & & \\
\hline T2 & $x$ & $\mathrm{x}$ & $\mathrm{x}$ & $\mathrm{x}$ & $\mathrm{x}$ & $\mathrm{x}$ & $\mathrm{x}$ & $\mathrm{x}$ & $x$ & $x$ & & $\mathrm{x}$ & $\mathrm{x}$ & $\mathrm{x}$ & $\mathrm{x}$ & $\mathrm{x}$ & $\mathrm{x}$ & $\mathrm{x}$ & $\mathrm{x}$ & $\mathrm{x}$ & $\mathrm{x}$ & $\mathrm{x}$ & $\mathrm{x}$ & $\mathrm{x}$ & $\mathrm{x}$ & $\mathrm{x}$ & $x$ & $\mathrm{x}$ & $\mathrm{x}$ & $\mathrm{x}$ \\
\hline T3 & & & & & & & & & & & & & & & & & & & & & & & & & & & & & & \\
\hline $\mathrm{T} 4$ & & & & & & & & & & & $\mathrm{x}$ & & & & & & & & & & & & & & & & & & & \\
\hline S1 & $\mathrm{x}$ & $\mathrm{x}$ & & $\mathrm{x}$ & & & $\mathrm{x}$ & & $\mathrm{x}$ & & & $\mathrm{x}$ & $\mathrm{x}$ & $\mathrm{x}$ & $\mathrm{x}$ & $\mathrm{x}$ & $\mathrm{x}$ & $\mathrm{x}$ & & $\mathrm{x}$ & $\mathrm{x}$ & $\mathrm{x}$ & $\mathrm{x}$ & $\mathrm{x}$ & $\mathrm{x}$ & $\mathrm{x}$ & $\mathrm{x}$ & $\mathrm{x}$ & & $\mathrm{x}$ \\
\hline S4 & & & & & & & & & & & & & & & & & & & & & & & & & & & & & & \\
\hline S5 & & & & $x$ & & & & & $\mathrm{x}$ & & & $x$ & & & & & & & & & & & & & & & & & & \\
\hline S6 & & & & & & & & & $x$ & & & & & & & & & & & & & & & & & & & & & \\
\hline S10 & & & & & & & & & & & $\mathrm{x}$ & & & & & & & & & & & & & & & & & & & \\
\hline V1 & $\mathrm{x}$ & $\mathrm{x}$ & $x$ & $\mathrm{x}$ & & & $x$ & & & & $\mathrm{x}$ & $\mathrm{x}$ & $\mathrm{x}$ & $\mathrm{x}$ & $\mathrm{x}$ & $\mathrm{x}$ & $x$ & $\mathrm{x}$ & $\mathrm{x}$ & & & $\mathrm{x}$ & $\mathrm{x}$ & $\mathrm{x}$ & $\mathrm{x}$ & $\mathrm{x}$ & $\mathrm{x}$ & $\mathrm{x}$ & $\mathrm{x}$ & \\
\hline V3 & $\mathrm{x}$ & $\mathrm{x}$ & $\mathrm{x}$ & & $\mathrm{x}$ & $\mathrm{x}$ & & $\mathrm{x}$ & $\mathrm{x}$ & $\mathrm{x}$ & & $\mathrm{x}$ & $\mathrm{x}$ & $\mathrm{x}$ & $\mathrm{x}$ & $\mathrm{x}$ & $\mathrm{x}$ & & & & & $x$ & $\mathrm{x}$ & $\mathrm{x}$ & $\mathrm{x}$ & $\mathrm{x}$ & $\mathrm{x}$ & $\mathrm{x}$ & & \\
\hline VA & & & & $\mathrm{x}$ & & & & & & & & & & & & & & & & & & & & & & & & & & \\
\hline P1 & & $\mathrm{x}$ & $\mathrm{x}$ & $\mathrm{x}$ & $\mathrm{x}$ & & $x$ & $\mathrm{x}$ & $\mathrm{x}$ & $\mathrm{x}$ & $x$ & $x$ & $\mathrm{x}$ & $\mathrm{x}$ & & $\mathrm{x}$ & $\mathrm{x}$ & $\mathrm{x}$ & $\mathrm{x}$ & $\mathrm{x}$ & $\mathrm{x}$ & & $\mathrm{x}$ & $x$ & $\mathrm{x}$ & $\mathrm{x}$ & $\mathrm{x}$ & $\mathrm{x}$ & $\mathrm{x}$ & $\mathrm{x}$ \\
\hline P8 & $x$ & $\mathrm{x}$ & & & & & & & & & & & & & & & & & & & & & & & & & & & & \\
\hline M1 & & $\mathrm{x}$ & & & & $\mathrm{x}$ & & & & & & & & & & & & & & & & & & & & & & & & \\
\hline MA & & $\mathrm{x}$ & & & & & & & & & & & & & $\mathrm{x}$ & $\mathrm{x}$ & & & & & & & & & $\mathrm{x}$ & $\mathrm{x}$ & & & & \\
\hline L1 & & $\mathrm{x}$ & & & & & & & & & & $\mathrm{x}$ & & & $x$ & & & & $x$ & & & & & & $\mathrm{x}$ & & & & $\mathrm{x}$ & \\
\hline
\end{tabular}

\begin{tabular}{|l|l|l|l|l|l|l|l|l|l|l|l|l|l|l|l|l|l|l|l|l|l|l|}
\hline 31 & 32 & 33 & 34 & 35 & 36 & 37 & 38 & 39 & 40 & 41 & 42 & 43 & 44 & 45 & 46 & 47 & 48 & 49 & 50 & 51 & 52 & F \\
\hline & & & & & & & & & & & & & & & & & & & & & & \\
\hline & $\mathrm{x}$ & $\mathrm{x}$ & $\mathrm{x}$ & $\mathrm{x}$ & $\mathrm{x}$ & $\mathrm{x}$ & $\mathrm{x}$ & & $\mathrm{x}$ & $\mathrm{x}$ & $\mathrm{x}$ & $\mathrm{x}$ & $\mathrm{x}$ & $\mathrm{x}$ & $\mathrm{x}$ & & $\mathrm{x}$ & $\mathrm{x}$ & & & & 46 \\
\hline & & & & & & & & & & & & & & & & & & & & & 0 \\
\hline $\mathrm{x}$ & $\mathrm{x}$ & $\mathrm{x}$ & $\mathrm{x}$ & $\mathrm{x}$ & $\mathrm{x}$ & $\mathrm{x}$ & $\mathrm{x}$ & & $\mathrm{x}$ & $\mathrm{x}$ & $\mathrm{x}$ & $\mathrm{x}$ & $\mathrm{x}$ & $\mathrm{x}$ & $\mathrm{x}$ & & $\mathrm{x}$ & $\mathrm{x}$ & & $\mathrm{x}$ & $\mathrm{x}$ & 41 \\
\hline & & & & & & & & & & & & & & & & & & & $\mathrm{x}$ & & & 1 \\
\hline & & & & & & & & & & & & & & & & & & & $\mathrm{x}$ & $\mathrm{x}$ & 5 \\
\hline & & & & & & & & & & & & & & & & & & & & & & 1 \\
\hline & $\mathrm{x}$ & $\mathrm{x}$ & $\mathrm{x}$ & $\mathrm{x}$ & $\mathrm{x}$ & $\mathrm{x}$ & $\mathrm{x}$ & $\mathrm{x}$ & $\mathrm{x}$ & $\mathrm{x}$ & $\mathrm{x}$ & $\mathrm{x}$ & & $\mathrm{x}$ & $\mathrm{x}$ & $\mathrm{x}$ & $\mathrm{x}$ & $\mathrm{x}$ & & & & 39 \\
\hline & & & & & & & & & & & & & & & & & & & & & 1 \\
\hline $\mathrm{x}$ & & $\mathrm{x}$ & $\mathrm{x}$ & $\mathrm{x}$ & $\mathrm{x}$ & & & $\mathrm{x}$ & $\mathrm{x}$ & $\mathrm{x}$ & $\mathrm{x}$ & $\mathrm{x}$ & $\mathrm{x}$ & $\mathrm{x}$ & & $\mathrm{x}$ & $\mathrm{x}$ & & & & & 41 \\
\hline & $\mathrm{x}$ & & & & & $\mathrm{x}$ & & & & & & & $\mathrm{x}$ & & & & & & & & 6 \\
\hline & & & & & & & & & & & & & & & & & & & & & & \\
\hline
\end{tabular}


A partir dos dados da Tabela 7 e das tabelas de codificações foi elaborada a Figura 4, contendo a matriz binária (peça $x$ máquina) de incidência de peças, a qual denota em quais máquinas as peças são processadas.

Do ponto de vista teórico, esse procedimento fornece resultados satisfatórios. Entretanto, ele não garante a solução ótima. De fato, o principal problema no agrupamento de máquinas é que a solução ótima pode cair no caso conhecido na literatura como NP-completo (WANG, 2003). Portanto, a aplicação da classificação SICGE, embora não forneça a melhor solução do ponto de vista teórico, na presente pesquisa forneceu uma solução considerada satisfatória, permitindo construir uma matriz capaz de apontar em quais máquinas as peças eram processadas.

Após a elaboração da matriz peça-máquina, foi necessário construir a tabela de listagem de máquinas-chave, segundo a classificação SICGE e F (números diferentes de peças que passam em cada máquina) em forma ascendente em cada categoria da classificação. Por exemplo, na categoria $S$, temos em F: 2,6,6,11 e 12, então colocados nessa ordem, conforme mostrado na Tabela 9.

Para a construção da tabela de módulo resumido (Tabela 10), foi necessário explorar os dados e informações da matriz de incidência de peças (Figura 4) e da listagem de máquinas-chave (Tabela 9). Por exemplo, o módulo 14 (Tabela 9) tem duas peças, sendo que uma procede da máquina P8 (solda elétrica) e a outra da V3 (viradeira), as quais pertencem aos módulos 12 e 10 respectivamente.

Analisando-se a Tabela 10 também é possível constatar que, por exemplo, S1 faz operações em 41 peças $(F)$, sendo que, desse total, duas são originárias da máquina T4 (peças 51 e 52) e 39 vêm da máquina T2 (peças $1,2,4,7,9,12, \ldots$ e 49). Então: $F(S 1)=f(T 4)+f(T 2)=2+$ $39=41$.

O objetivo de se construir o módulo resumido é subsidiar o planejamento e formação dos grupos de máquinas que irão compor as células de manufatura.

\section{Formação de grupos}

O objetivo nessa etapa é a seleção dos grupos e dos módulos para formarem o núcleo de cada grupo experimental. A execução dessa etapa foi conduzida conforme os seguintes passos: i) planejamento dos grupos e escolha dos núcleos e ii) seleção dos grupos.

\section{Planejamento dos grupos e escolha dos núcleos}

O principal objetivo na formação de grupos é encontrar conjuntos de peças (famílias) que possam ser terminadas apenas por um conjunto próprio de máquinas.

Conhecendo-se que tipos de peças são produzidas, pode-se então escolher os grupos e encontrar os conjuntos de módulos prováveis para formar os núcleos destes grupos. Como exemplo, temos os grupos de máquinas pesadas. Os núcleos desses grupos podem ser formados

Tabela 9: Listagem de máquinas-chave segundo a classificação SICGE e F ascendente.

\begin{tabular}{|c|c|c|c|c|c|}
\hline \multicolumn{3}{|c|}{ MÁQUINA-CHAVE } & \multirow{2}{*}{ SICGE } & \multirow{2}{*}{$\mathbf{N}$} & \multirow{2}{*}{$\mathbf{F}$} \\
\hline Módulo & CÓDIeO & NOME & & & \\
\hline 14 & M1 & Solda mig & $\mathrm{S}$ & 1 & 2 \\
\hline 1 & T4 & Tesoura & $\mathrm{S}$ & 1 & 6 \\
\hline 12 & P8 & Solda elétrica & $S$ & 1 & 6 \\
\hline 15 & MA & Solda maçarico & $\mathrm{S}$ & 1 & 11 \\
\hline 16 & L1 & Lixadeira manual & $\mathrm{S}$ & 1 & 12 \\
\hline 9 & V1 & Viradeira & 1 & 3 & 37 \\
\hline 6 & S4 & Prensa & C & 1 & 1 \\
\hline 7 & S6 & Prensa & C & 3 & 1 \\
\hline 8 & S10 & Prensa & C & 1 & 4 \\
\hline 5 & S5 & Prensa & C & 1 & 5 \\
\hline 10 & V3 & Viradeira & C & 2 & 39 \\
\hline 4 & S1 & Prensa & $\mathrm{C}$ & 3 & 41 \\
\hline 13 & P1 & Solda elétrica & C & 6 & 41 \\
\hline 3 & T3 & Tesoura & $\mathrm{G}$ & 1 & 0 \\
\hline 2 & T2 & Tesoura & $G$ & 1 & 46 \\
\hline 11 & VA & Viradeira manual & $E$ & 2 & 1 \\
\hline
\end{tabular}


por módulos nos quais as máquinas-chave são laminadoras planas, máquinas de perfuração horizontal ou retificadora ou ainda o grupo de máquinas rotacionais caracterizadas pela fabricação de grandes peças circulares, como anéis, rodas e discos. Os módulos são baseados em máquinas de perfuração vertical ou grandes furadeiras radiais. Pode-se ainda citar o caso do grupo de engrenagens, caracterizado por peças que são geralmente feitas em máquinas especiais para este propósito, como as fresas ou o grupo de tornos, no qual os módulos que possuem tornos como máquinas-chave, provavelmente, formarão núcleos adequados para este grupo.

Um bom planejamento dos grupos e escolha dos núcleos tem uma grande influência no resultado final da seleção dos grupos, isto é, o planejamento dos grupos está diretamente relacionado à similaridade de máquinas e à formação de grupos de máquinas capazes de perfazer operações de transformação em um conjunto ou família de peças, que possuem características geométricas ou de processamento similares.

\section{Seleção dos grupos}

Um dos principais objetivos na seleção e formação de grupos de máquinas em células está relacionado com o seqüenciamento da produção, um problema relativamente complexo com grandes reflexos no tempo de setup, no tamanho dos lotes de produção, no estoque de produtos em processo e nos indicadores econômicos e financeiros da empresa. A determinação de uma seqüência operacional ótima para uma dada peça ou família de peças não é uma tarefa trivial. Por exemplo, para $n$ tarefas ou trabalhos (jobs) e $m$ máquinas, todas as combinações possíveis para seqüenciar todas as tarefas é igual a $(\mathrm{n})^{\mathrm{m}}$

Embora o presente trabalho não se proponha a discutir o problema de seqüenciamento, fica evidenciada a importância e contribuição da MC na solução de problemas de seqüenciamento da produção, principalmente nas empresas com elevado mix de produtos e layout caracterizado por fluxos cruzados, como é o caso da empresa em discussão.

A seleção de grupos de máquinas foi feita através da combinação de módulos, utilizando-se a tabela de módulo resumido. O seguinte algoritmo foi utilizado no processo de seleção de grupos (BURBIDGE 1989):

a) verificar os $f$ de cada módulo para formar os grupos, sabendo que $\mathrm{F}=\Sigma(\mathrm{f})$;

b) determinar os grupos baseados em módulos de classe $\mathrm{S}$ (especial) e I (intermediária) e selecionar esses módulos como núcleos. Uma análise da Tabela 10 revela os seguintes módulos:

- classe S: 14, 1, 12, 15 e 16;

- classe I: apenas o módulo 9;

c) selecionar os grupos baseados em módulos de classe $\mathrm{C}$ (comum) ou agrupar esses módulos a grupos já existentes:

- classe C: 6, 7, 8, 5, 10, 4 e 13;

Tabela 10: Listagem de máquinas chave segundo a classificação SICGE e F ascendente

\begin{tabular}{|c|c|c|c|c|c|c|c|c|c|c|c|c|c|c|c|c|c|c|c|c|c|}
\hline \multicolumn{6}{|c|}{ MÁQUINA-CHAVE } & \multicolumn{16}{|c|}{ MóDULO E (F) } \\
\hline MóDULO & CóD. & NOME & $\mathbf{N}$ & $F$ & SICEE & $\#$ & 1 & $\#$ & 15 & $\#$ & 9 & 6 & 7 & 8 & 5 & $\#$ & 4 & $\#$ & 3 & 2 & 11 \\
\hline 14 & M1 & Solda mig & 1 & 2 & $S$ & & & 1 & & & & & & & & 1 & & & & & \\
\hline 1 & T4 & Tesoura & 1 & 6 & $S$ & & 6 & & & & & & & & & 3 & & & & & \\
\hline 12 & P8 & Solda elétrica & 1 & 6 & $\mathrm{~S}$ & & & & & & & & & & & & & 3 & & & \\
\hline 15 & MA & Solda maçarico & 1 & 11 & $S$ & 1 & & & & & & & & & & 1 & & 9 & & & \\
\hline 16 & L1 & Lixadeira man. & 1 & 12 & $\mathrm{~S}$ & & & & 5 & & & & & & 2 & & & 5 & & & \\
\hline 9 & V1 & Viradeira & 3 & 37 & I & & & & & & & & & 1 & 2 & & 31 & & & 3 & \\
\hline 6 & S4 & Prensa & 1 & 1 & C & & 1 & & & & & & & & & & & & & & \\
\hline 7 & S6 & Prensa & 3 & 1 & C & & & & & & & & & & 1 & & & & & & \\
\hline 8 & S10 & Prensa & 1 & 4 & C & & & & & & & 1 & & & & & & & & & \\
\hline 5 & S5 & Prensa & 1 & 5 & C & & 3 & & & & & & & & & & 5 & & & & \\
\hline 10 & V3 & Viradeira & 2 & 39 & C & & & & & & 32 & & & 2 & & & & & & 5 & \\
\hline 4 & S1 & Prensa & 3 & 41 & $\mathrm{C}$ & & 2 & & & & & & & & & & & & & 39 & \\
\hline 13 & P1 & Solda elétrica & 6 & 41 & C & & & & & & 4 & & & & & 31 & 5 & & & & 1 \\
\hline 3 & T3 & Tesoura & 1 & 0 & $G$ & & & & & & & & & & & & & & & & \\
\hline 2 & $\mathrm{T2}$ & Tesoura & 1 & 46 & $G$ & & & & & & & & & & & & & & & 46 & \\
\hline 11 & VA & Viradeira man. & 2 & 1 & $E$ & & & & & & 1 & & & & & & & & & & \\
\hline
\end{tabular}


d) Identificar módulos de classes G (geral) e E (equipamento) para formar grupos adicionais ou adicionar estes módulos aos grupos que já foram formados:

- classe G: 3 e 2;

- classe E: apenas o módulo 11.

e) os grupos poderão se unir, desde que haja compatibilidade entre os módulos.

No caso em análise, as tesouras (grupo 1) foram usadas para operações em todas as peças. Assim, o grupo de tesouras foi instalado no estágio de preparação (início do processo produtivo). Logo em seguida, nota-se a formação de dois grupos de prensas, pois o fluxo de peças está dividido, como pode ser verificado na tabela de módulo resumido: o grupo 2 (S1, S5, S6) faz operações com as peças que vêm do grupo das tesouras (T2, T3, T4) e existe uma dependência entre as máquinas deste grupo. No grupo 3 (S4 e S10), as peças também vêm do grupo das tesouras, existindo uma dependência entre estas máquinas. Entretanto, notas-se que as operações feitas por este grupo não dependem do grupo 2.

No caso da solda MA, essa não pôde ser unida ao grupo 5 porque violou a restrição de compatibilidade entre os processos. A formação de grupos está sumarizada na Tabela 11.

$\mathrm{Na}$ etapa seguinte, uniram-se as informações dos gru-

Tabela 11: Relação de grupos segundo os estágios.

\begin{tabular}{|c|c|}
\hline ESTÁGIOS & GRUPOS (G) \\
\hline 1 & 1 \\
\hline 2 & $2,3,4$ \\
\hline 3 & $5,6,7$ \\
\hline 4 & 8 \\
\hline 5 & 9 \\
\hline 6 & 10 \\
\hline
\end{tabular}

pos segundo os estágios de fabricação, de acordo com as informações contidas na Figura 12 (módulo resumido). O resultado encontra-se sumarizado na Tabela 12 .

A formação de grupo de máquinas em células é a etapa final. Com os seis estágios estabelecidos anteriormente e utilizando-se os dados da Tabela 8, foi possível determinar os grupos e as respectivas máquinas que compunham cada grupo, conforme mostrado na Figura 5.

Do ponto de vista de qualidade da solução obtida, na formação de grupo de máquinas em células, podem-se utilizar métodos exatos ou métodos heurísticos. Os métodos exatos são baseados em programação matemática, notadamente a programação inteira, e conseguem resolver em um tempo computacional adequado apenas problemas de pequeno porte. Como a formação de famílias de peças e a formação de grupos de máquinas em células é um problema NP-completo, cuja obtenção da solução ótima conduz a tempos computacionais elevadíssimos e, portanto, inviáveis economicamente. Os procedimentos heurísticos como os utilizados no presente estudo são capazes de fornecer soluções consideradas de boa qualidade com um investimento de tempo baixo em relação aos métodos exatos.

Quando a formação de grupos de máquinas é conduzida de maneira adequada, a tarefa de seqüenciamento dos trabalhos (jobs) nas células torna-se mais simplificada, reduzindo os tempos de setup e conseqüentemente os tamanhos dos lotes, com reflexo positivo na redução dos estoques de produtos em processo e na elevação do giro de estoque.

Uma das deficiências da análise do fluxo de fabricação, assim como dos demais métodos baseados na matriz de incidência peça-máquina, é que ela não considera explicitamente nem a capacidade das máquinas, nem o volume de produção.

Tabela 12: Relação de máquinas segundo módulos e grupos.

\begin{tabular}{|c|c|c|}
\hline GRUPOS (G) & MÓDULOS & MÁQUINAS-GHAVE \\
\hline 1 & $1,2,3$ & T4,T2,T3 \\
\hline 2 & $4,5,7$ & $\mathrm{~S} 1, \mathrm{~S} 5, \mathrm{~S} 6$ \\
\hline 3 & 6,8 & $\mathrm{~S} 4, \mathrm{~S} 10$ \\
\hline 4 & $9,10,11$ & $\mathrm{~V} 1, \mathrm{~V} 3, \mathrm{VA}$ \\
\hline 5 & $12,13,14$ & $\mathrm{P} 8, \mathrm{P} 1, \mathrm{M} 1$ \\
\hline 6 & 15 & $\mathrm{MA}$ \\
\hline 7 & 16 & $\mathrm{~L} 1$ \\
\hline 8 & $\ldots$ & $\mathrm{LM}$ \\
\hline 9 & $\ldots$ & $\mathrm{Pl}$ \\
\hline 10 & $\ldots$ & $\mathrm{MF}$ \\
\hline
\end{tabular}


No caso de pequenas e médias empresas, as máquinas geralmente têm múltiplas funções ou um grupo de máquinas com a mesma funcionalidade, de modo que, teoricamente, mudar uma operação de uma máquina para outra pode reduzir o fluxo intercelular, ou dois lotes de uma mesma peça poderiam ser processados através de dois diferentes roteiros de produção. Nesse caso, o objetivo principal do problema passaria a ser a minimização do fluxo intercelular, o que não é o caso do presente estudo. Entretanto, para melhorar a qualidade da solução obtida, seria recomendável um aprofundamento no sentido de também considerar o caso de fluxo intercelular.

\section{CONCLUSÃo}

A aplicação da metodologia de manufatura celular análise do fluxo de fabricação na indústria moveleira mostrou-se bastante eficiente. Como resultado, obteve-se um melhor reordenamento das operações-chave de produção. Além disso, a obtenção de fluxos mais simples implicou uma maior facilidade para planejar e controlar as operações e ao mesmo tempo reduziu os tempos totais de fabricação, aumentando desta forma a competitividade da empresa. Isso pode ser efetivado graças à racionalização da movimentação de peças entre máquinas, seções, departamentos e à eliminação de fluxos cruzados. A simplificação dos fluxos de produção permitiu também a reorganização das operações de produção agrupando fluxos de produtos, componentes e pecas similares em famílias.

Apesar do presente artigo não ter se aprofundado nos indicadores sociais, várias conclusões feitas por Yauch e Steudel (2002) puderam ser observadas na empresa em estudo, notadamente os fatores mobilidade, sistema organizacional fraco fortemente influenciado pela administração familiar e excesso de ênfase em atividades rotineiras em detrimento de questões estratégicas. Esses fatores constituem fortes barreiras à adoção de um sistema de manufatura celular em pequenas empresas.

Várias oportunidades de pesquisas futuras sobre o tema podem ser levantadas, como, por exemplo, investigar como explicitamente introduzir no modelo AFF o problema da minimização do fluxo intercelular. Outra possibilidade de pesquisa é a consideração simultânea de variáveis como capacidade e mix de produção. A aplica-

Figura 5: Formação de grupos em células de fabricação.

ESTÁGIO 1


ção de metaeurísticas como a abordagem simulated annealing, pode ser utilizada na formação de grupo de máquinas e famílias de peças considerando o tempo de processamento e a capacidade das máquinas.
Uma terceira via de pesquisa é o estudo de como a cultura organizacional impacta o processo de implementação de um sistema de manufatura celular, principalmente no caso de pequenas e médias empresas brasileiras.

\section{Artigo recebido em 07/08/2002 Aprovado para publicação em 20/05/2005}

\section{- Referências Bibliográficas}

BROWN, L.D. Planned change in underorganization systems. In: CUMMINGS, T.G. (ed.), Systems theory for organization development. New York: Wiley, 1980.

BURBIDGE, J.L. Production flow analysis. Production engineer, v. $42, \mathrm{n}$. 12, p. 742-752, 1963.

BURBIDGE, J.L. Production flow analysis for planning group technology. Oxford: Clarendo Press, 1989.

BURBIDGE, J.L. Change to group technology: Process organization is obsolete. International journal of production research, Loughborough, v. 30, n. 5, p.1209-1219, 1992.

CHEN C.H.; GOH C.H.; LEE A. Designing group technology manufacturing systems using heuristics branching rules. Computers $\mathcal{E}$ industrial engineering, New York, v. 40, n. 1-2, p. 117-131, 2001.

CHING,Y.C.; LAM, F.W.; LEE,C,P. Considerations for using cellular manufacturing. Journal of materials processing technology, New York, v. 96 n. $1-3$, p. $182-187,1999$

GRZNAR J. Part family formation for variety reduction in flexible manufacturing systems. International journal of operations \& production management, Bradford, v. 17, n. 3, p. 291-295, 1997.

HASSAM, M.M.D. Layout design in group technology manufacturing. International Journal of Production Economics, New York, v. 38, n. 2-3, p. 173-188, 1995.
HYER, N.L.; BROWN, K.A. The discipline of real cells. Journal of operations management, v. 17 , p. 557 574, 1999.

KANNAN R.V; PALOCSAY S.W. Cellular vs process layouts: an analytic investigation of the impact of learning on shop performance, New York: Omega. v. 27, n. 5, p. 583592, 1999.

KUSIAK, A. The part families problem in flexible manufacturing systems. Annals of operational research, v. 3, p. 279-300, 1985

KUSIAK, A. The generalized group technology concept. International journal of production research, Loughborough, v. 25, p. 561-569, 1987.

KUSIAK, A.; CHOW, W.S. Efficient solving of group technology problem. Journal of manufacturing systems, Dearborn, v. 6, n. 2, p. 117-124, 1987.

LARI-BAZARGAN, M. Layout designs in cellular manufacturing. European journal of operations research, London, v. 112, n. 2, p. 258-272, 1999.

LIANG M.; ZOLFAGHARI S. Machine cell/part family formation considering processing times and machine capacities: a simulated annealing approach. Computers $\mathcal{E}$ industrial engineering, New York, v. 34, n. 4 , p. 813-823, 1998.

MELLER, R.D.; GAU K.Y. The facility layout problem: recent and emerging trends and perspectives. Journal of manufacturing systems, Ann Arbor, v.15, n.5, p. 351-366, 1996.
PROUDLOVE, N.C.; VADERÁ, KOBBACY, K. Intelligent management systems in operations: a review. Journal of operational research society, Oxford, v. 49, n. 7, p. 682-699, 1998.

OLORUNNIWO, F.; UDO, G. The impact of management and employees on cellular manufacturing implementation. International Journa of Production Economics, v. 76, n. 1, p. 27-38, 2002.

REISMAN, A.; KUMAR, A.; MOTWANI, J.; CHENG, C.H. Cellular manufacturing: a statistical review of the literature (1965-1995). Operations research, Linthicum, v. 45 , n. 4, p. 508-520, 1997.

SELIM H.M.; ASKIN R.G.; VAKHARIA A. J. Cell formation in group technology: review, evaluation and directions for future research. Computers \& Industrial Engineering. New York, v. 34, n. 1, p. 3-20, 1998.

SINGH, N. Design of cellular manufacturing systems: An invited review. European journal of operationa research, London, v. 69 , n. 3, p. 284 291, 1993.

SLOMP, J.; ZIJM, W.H.M. A manufacturing planning and control system for a flexible manufacturing system. Robotics \& computer integrated manufacturing, London, v. 10, n. 1-2, p. $109-114,1993$.

TAM, K.Y. An operation sequence based similarity coefficient for parts families formation. Journal of manufacturing systems, Dearborn, v. 9 n. 1 , p. $55-68,1990$
VENUGOPAL, V.; NARENDRAN, T.T. Machine cell formation through neural network models. International journal of production research, Loughborough, v. 32 , n. 9, p. $2105-$ 2116, 1994.

VENUGOPAL, V. Soft computingbased approaches to the group technology problem: A state of the art review. International journal of production research, Loughborough, v. 37, n. 14, p. 3335-3357, 1999.

WANG, J. Formation of machine cells and part families in cellular manufacturing systems using a linear assignment algorithm, New York, v. 39, n. 9, p. 1607-1615, 2003.

WEI, J.C.; KERN, G.M. Commonality analysis: A linear cell clustering algorithm for group technology. International journal of production research, Loughborough, v. 27, p. 2053-2062, 1989.

WEMMERLOV, U.; JOHNSON, D.J. Cellular manufacturing at 46 use plants: implementation, experiences and performance improvements. International journal of production research, Loughborough, v. 35, n. 1, p. 29-49, 1997.

XAMBRE, A.; VILARINHO, P.M. A simulated annealing approach for manufacturing cell formation with multiple identical machines, London, v. 151, n. 2, p. 434-446, 2003.

YAUCH, A.C.; STEUDEL, H. Cellular manufacturing for small businesses: key cultural factors that impact the conversion process. Journal of operations management. v. 20, n. 5 , p. 593-617, 2002

YIN, R.K. Case study research: Design and methods, 2. ed. Thousand Oaks: Sage publication, 1994.

\section{- Sobre o autor}

\section{Samuel Vieira Conceição}

Departamento de Engenharia de Produção - UFMG

Caixa Postal 209 - CEP 30161-970 - Belo Horizonte - MG

Tel.: (31) 3499-4882

E-mail: svieira@dep.ufmg.br 